\title{
Point-of-care test of heart-type fatty acid-binding protein for the diagnosis of early acute myocardial infarction
}

\author{
Chun-jian $\mathrm{LI}^{1, *}$, Jie-qi $\mathrm{LI}^{2}$, Xiao-fang $\mathrm{LIANG}^{1}$, Xiao-xiang $\mathrm{LI}^{2}$, Jian-guo $\mathrm{CUI}^{1}$, Zhi-jian YANG ${ }^{1}$, Qing GUO ${ }^{3}$, Ke-jiang $\mathrm{CAO}^{1}$, \\ Jun HUANG ${ }^{1}$ \\ ${ }^{1}$ Department of Cardiology, The First Affiliated Hospital of Nanjing Medical University, Nanjing 210029, China; ${ }^{2}$ Department of Cardiol- \\ ogy, The Affiliated Hospital of Guiyang Medical College, Guiyang 550004, China; ${ }^{3}$ Population Health Research Institute, MacMaster \\ University, 237 Barton Street East, Hamilton, ON L8L 2X2, Canada
}

\begin{abstract}
Aim: To investigate the efficacies of point-of-care test of heart-type fatty-acid binding protein (H-FABP) and its combinations with the conventional biomarkers in the diagnosis of early acute myocardial infarction (AMI).

Methods: 227 patients suspected of AMI were consecutively recruited in two centers. Biomarkers including H-FABP, myoglobin (MYO), creatine kinase-myocardial band (CK-MB) and cardiac troponin T (cTnT) were determined simultaneously at admission. AMI was defined according to the universal definition of myocardial infarction. Chi-Square test was adopted for the analysis.

Results: In patients presenting within 12 h of symptom onset, the sensitivity of H-FABP[93.0\% (95\% Cl: 86.6\%-96.9\%)] was significantly higher than that of initial CK-MB [67.5\% (95\% Cl: 58.1\%-76.0\%), $P<0.0001]$, cTnT [69.3\% (95\%Cl: 60.0\%-77.6\%), P<0.0001] and MYO [68.6\% (95\% Cl: 54.1\%-80.9\%), P<0.05]. The negative predictive value of H-FABP [92.8\% (95\%Cl: 86.3\%-96.8\%)] was significantly higher than that of initial CK-MB [74.7\% (95\% Cl: 66.8\%-81.5\%), P<0.001] and cTnT [75.9\% (95\% Cl: 68.1\%-82.6\%), $P<0.001]$. The sensitivity of H-FABP+cTnT combination [94.7\% (95\% Cl: 88.9\%-98.0\%)] was significantly higher than that of admission cTnT [69.3\% (95\% Cl: 60.0\%-77.6\%), P<0.0001], CK-MB+cTnT [75.4\% (95\% Cl: 66.5\%-83.0\%), P<0.0001] and MYO+CK-MB+cTnT [74.5\% (95\% Cl: 60.4\%-85.7\%), P<0.05]. The negative predictive value of H-FABP+cTnT [94.5\% (95\% Cl: 88.4\%-98.0\%] was significantly higher than that of initial cTnT [75.9\% (95\% Cl: 68.1\%-82.6\%), P<0.001] and CK-MB+cTnT [79.1\% (95\% Cl: 71.2\%-85.6\%), $P<0.001$ ]. Subgroup analysis showed that the superiorities of both the sensitivities and the negative predictive values of $\mathrm{H}-\mathrm{FABP}$ and $\mathrm{H}-\mathrm{FABP}+\mathrm{CTnT}$ combination occurred only in patients who presented within $6 \mathrm{~h}$ of the symptom onset.

Conclusion: Point-of-care test of H-FABP can be used as a valuable biomarker to detect or exclude an early-stage AMI. Combining $\mathrm{H}-\mathrm{FABP}$ and $\mathrm{CTnT}$ provides the best performance for early AMI diagnosis.
\end{abstract}

Keywords: point-of-care test; heart-type fatty-acid binding protein; acute myocardial infarction; diagnosis

Acta Pharmacologica Sinica (2010) 31: 307-312; doi: 10.1038/aps.2010.2; published online 5 February 2010

\section{Introduction}

Acute myocardial infarction (AMI) is a primary life-threatening cardiac disease, early and correct diagnosis is of great importance to enable immediate and intensified treatment which consequently reduces mortality ${ }^{[1-3]}$. Unfortunately, at least one-fifth of AMIs are clinically unrecognized because of absence of chest discomfort or atypical ECG changes ${ }^{[4]}$. Thus, early AMI diagnosis relies crucially on the biochemical markers in these cases.

Heart-type fatty acid-binding protein (H-FABP) is a small

\footnotetext{
* To whom correspondence should be addressed. E-mail lijay@njmu.edu.cn

Received 2009-10-05 Accepted 2010-01-06
}

cytoplasmic protein which is abundantly expressed in human heart $^{[5]}$. It was first shown to be released from injured myocardium in 1988, after which its application as a biochemical marker has been investigated ${ }^{[6,7]}$. Recently, the point-of-care immunochromatographic assay of H-FABP has been created to achieve a rapid determination of the whole blood H-FABP level. However, researches have shown inconsistent performances of H-FABP rapid penal test in the diagnosis of AMI. So the priority of H-FABP is worthy of further investigation.

We conducted this study in two centers to determine the value of the point-of-care test of H-FABP alone and in combination with CTnT in early AMI diagnosis, and hypothesized that, 1) H-FABP is superior to the conventional biomarkers in the diagnosis of early AMI; 2) Combining H-FABP and CTnT 
can improve the performance of single cTnT and is superior to other regular combinations.

\section{Materials and methods Study subjects}

This study was conducted in two centers simultaneously in accordance with the Declaration of Helsinki and was approved by the local ethics board. Patients presenting chest pain more than 30 min and less than $12 \mathrm{~h}$ suspected of AMI were enrolled consecutively in the study. Patients' symptoms and past medical history were documented at admission using a pre-defined protocol.

\section{Diagnostic criteria}

The standard diagnosis was made after critical review of all the clinical pictures and relevant information by a senior cardiologist. AMI was defined as detection of initial or $12 \mathrm{~h} \mathrm{cTnT}$ $\geq 0.1 \mathrm{ng} / \mathrm{mL}$ together with evidence of myocardial ischemia with at least one of the following: i) Symptoms of ischemia; ii) ECG changes indicative of new ischemia (new ST-T changes or new left bundle branch block [LBBB]); iii) Development of pathological $Q$ waves in the ECG; iv) Imaging evidence of new loss of viable myocardium or new regional wall motion abnormality ${ }^{[1]}$. Diagnostic outcomes were first categorized into the following groups: i) ST-elevation myocardial infarction (STEMI); ii) non-ST-elevation myocardial infarction (NSTEMI); iii) unstable angina (UA); iv) chronic angina (CA); and v) noncardiac chest pain $(\mathrm{NCCP})^{[1,2,8]}$. The first two groups were later integrated into AMI group, and the last three into nonmyocardial infarction (NMI) group.

\section{Determinations of H-FABP and other biomarkers}

Initial blood samples were collected from every subject upon hospital admission for the determinations of H-FABP and other biomarkers. A point-of-care H-FABP kit, using a rapid immunochromatographic method, was applied to qualitatively determine the H-FABP levels in whole blood samples with a cut-off level at $7 \mathrm{ng} / \mathrm{mL}$. The test was interpreted within $10 \mathrm{~min}$ after the blood was applied into the sample slot of the test strip, and the results were judged as positive or negative by different types of the color changes. Trained medical staff, blinded to the standard diagnosis, was qualified to perform the H-FABP test. The package of H-FABP kit (20Test/kit, Pattern number: HFABPM20, Batch № 20070620) was supplied by Wuhan EasyDiagnosis Biomedicine Co, Ltd (Wuhang, China) (Figure 1). MYO, CK-MB and cTnT were determined from the initial blood samples using the immunofluorescence method, dry chemistry analysis and the enzymelinked immunosorbent assay (ELISA) with cut-off levels of 46 $\mathrm{ng} / \mathrm{mL}, 25 \mathrm{U} / \mathrm{L}$ and $0.1 \mathrm{ng} / \mathrm{mL}$, respectively. Any results that were no less than the cut-off levels were defined as positive results. Conversely, those being less than the cut-off levels were defined as negative results. Regarding the combinations, positive results were defined as positive of any component markers, while negative results were defined as negative of all the component markers. cTnT was re-determined at least $12 \mathrm{~h}$

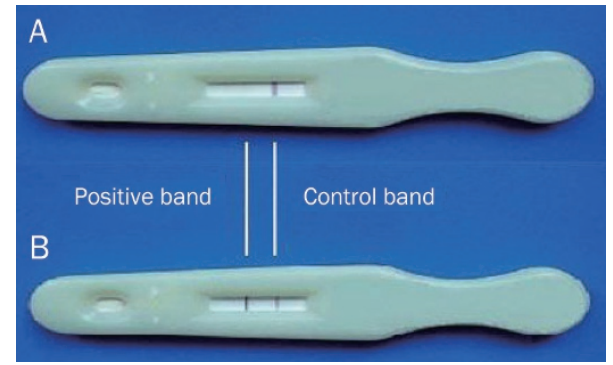

Figure 1. Point-of-care test of H-FABP. (A) Negative result: positive band remained pale while the control band turned red; $(B)$ Positive result: both the positive and the control bands turned red.

from the onset of the chest pain to fulfill a final diagnosis.

\section{Statistics}

All the data were analyzed in MacMaster University, Canada. SAS 9.1 analysis software was used for the statistics, data were expressed as mean $\pm S D$. Student's $t$ test and Chi-Square were used to compare the differences of the basic characteristics between AMI and NMI groups. Chi-Square test was also adopted to analyze the differences of the sensitivity, specificity, positive and negative predictive values. Fisher's exact test was used when any cell in the square was less than five. The level of significance was set at 0.05 .

\section{Results}

Patient characteristics

227 patients, 163 male and 64 female, average age $64.5 \pm 11.6$ years, were recruited in the period from Jan 2008 to Aug 2008. According to the diagnostic criteria, 114 patients were defined as AMI; 27 patients as UA; 20 patients as CA; and 66 patients as NCCP. Compared with the NMI patients, AMI patients were older, more likely to be male, more likely to have previous coronary artery disease, and more likely to have a heart function of New York class III and IV (Table 1). The average symptom-to-sample time (from symptom onset to initial blood sampling) of total AMI patients was $4.96 \pm 3.08 \mathrm{~h}$ (median 4 h), in which $38(33.3 \%)$ patients were admitted within $3 \mathrm{~h}$ $(2.03 \pm 0.80 \mathrm{~h}$; median $2 \mathrm{~h}), 44(38.6 \%)$ patients between 3 to $6 \mathrm{~h}$ $(4.44 \pm 0.68 \mathrm{~h}$; median $4.25 \mathrm{~h})$, and $32(28.1 \%)$ patients between 6 to $12 \mathrm{~h}(9.16 \pm 2.01 \mathrm{~h}$; median $9 \mathrm{~h})$ of symptom onset.

\section{Superiorities of H-FABP and its combinations}

$\mathrm{H}-\mathrm{FABP}, \mathrm{CK}-\mathrm{MB}$, and cTnT were measured in all the 227 subjects. The sensitivity of H-FABP [93.0\% (95\% CI: $86.6 \%-96.9 \%)]$ was significantly higher than that of initial CK-MB [67.5\% (95\% CI: 58.1\%-76.0\%), P<0.0001] and cTnT [69.3\%(95\% CI: 60.0\%-77.6\%), P<0.0001]. Similarly, the negative predictive value of H-FABP [92.8\% (95\% CI: $86.3 \%-96.8 \%)]$ was significantly higher than that of initial CK-MB [74.7\% (95\% CI: 66.8\%-81.5\%), P<0.001] and cTnT [75.9\% (95\% CI: $68.1 \%-82.6 \%), P<0.001]$. The sensitivity of H-FABP+cTnT combination [94.7\% (95\% CI: 88.9\%-98.0\%)] was significantly higher than that of admission cTnT $[69.3 \%$ 
Table 1. Patients' characteristics.

\begin{tabular}{|c|c|c|c|}
\hline Demographics & AMI $(n=114)$ & NMI $(n=113)$ & $P$ value \\
\hline Males $n,(\%)$ & $93(81.6)$ & $70(61.9)$ & 0.001 \\
\hline Age (years) & $67.1 \pm 11.1$ & $61.8 \pm 11.5$ & $<0.001$ \\
\hline Previous coronary artery disease $n,(\%)$ & $103(90.4)$ & $34(30.1)$ & $<0.001$ \\
\hline Hypertension $n,(\%)$ & $45(39.5)$ & $33(29.2)$ & 0.103 \\
\hline Diabetes $n,(\%)$ & $18(15.8)$ & $10(8.8)$ & 0.112 \\
\hline
\end{tabular}

(95\% CI: $60.0 \%-77.6 \%), P<0.0001]$ and CK-MB+cTnT [75.4\% (95\% CI: $66.5 \%-83.0 \%), P<0.0001]$. The negative predictive value of $\mathrm{H}-\mathrm{FABP}+\mathrm{CTnT}$ [94.5\% (95\% CI: 88.4\%-98.0\%] was also significantly higher than that of initial cTnT $[75.9 \%(95 \%$ CI: $68.1 \%-82.6 \%), P<0.001]$ and CK-MB+cTnT [79.1\% $(95 \%$ CI: $71.2 \%-85.6 \%), P<0.001]$. The sensitivity and negative predictive values of $\mathrm{H}-\mathrm{FABP}, \mathrm{H}-\mathrm{FABP}+\mathrm{cTnT}, \mathrm{H}-\mathrm{FABP}+\mathrm{CK}-$ $\mathrm{MB}+\mathrm{cTnT}$ had no significant difference. Also, the specificities and the positive predictive values of H-FABP, CK-MB, cTnT, $\mathrm{H}-\mathrm{FABP}+\mathrm{cTnT}, \mathrm{H}-\mathrm{FABP}+\mathrm{CK}-\mathrm{MB}+\mathrm{cTnT}$, and $\mathrm{CK}-\mathrm{MB}+\mathrm{cTnT}$ had no statistical difference (Figure 2,3).

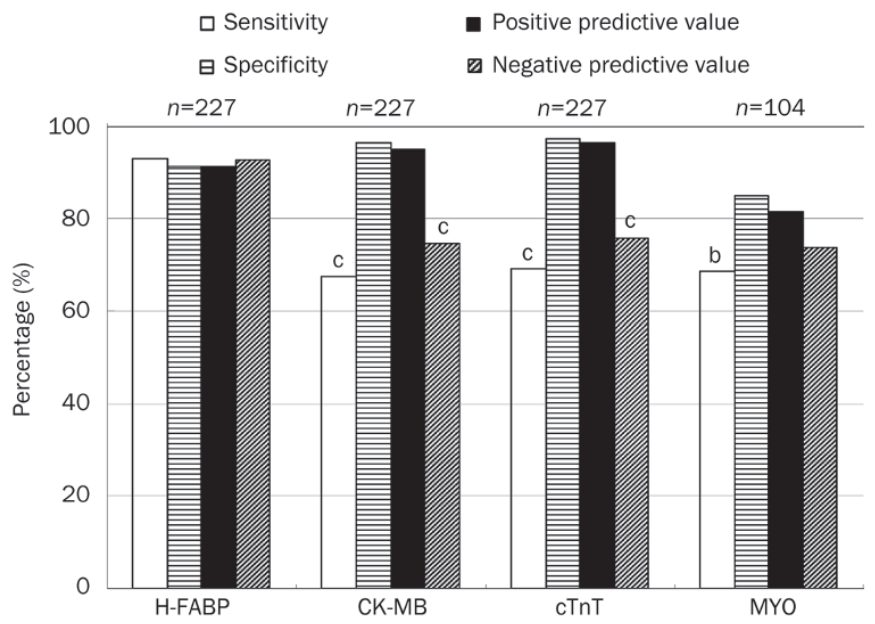

Figure 2. Sensitivity, specificity, positive and negative predictive values of different biomarkers. Compared with $\mathrm{H}-\mathrm{FABP},{ }^{\mathrm{b}} P<0.05,{ }^{\mathrm{c}} P<0.01$ (result from subgroup analysis).

\section{Performances of the biomarkers in different time windows}

We separated the patients into 3 subgroups by symptomto-sample time as: i) $\leq 3 \mathrm{~h}$; ii) $>3 \mathrm{~h}, \leq 6 \mathrm{~h}(3-6 \mathrm{~h})$; and iii) $>6 \mathrm{~h}$, $\leq 12 \mathrm{~h}(6-12 \mathrm{~h})$. The sensitivities of H-FABP of the three time windows were $84.2 \%$ (95\% CI: $68.7 \%-94.0 \%), 95.5 \%(95 \%$ CI: $84.5 \%-99.4 \%$ ) and $100 \%$ (95\% CI: $89.1 \%-100.0 \%)$, respectively, and the negative predictive values were $86.0 \%$ (95\% CI: $72.1 \%-94.7 \%$ ), $94.3 \%$ (95\% CI: $80.8 \%-99.3 \%$ ), and $100 \%(95 \%$ CI: $89.4 \%-100.0 \%)$ respectively. The sensitivity and negative predictive value of H-FABP were both significantly higher

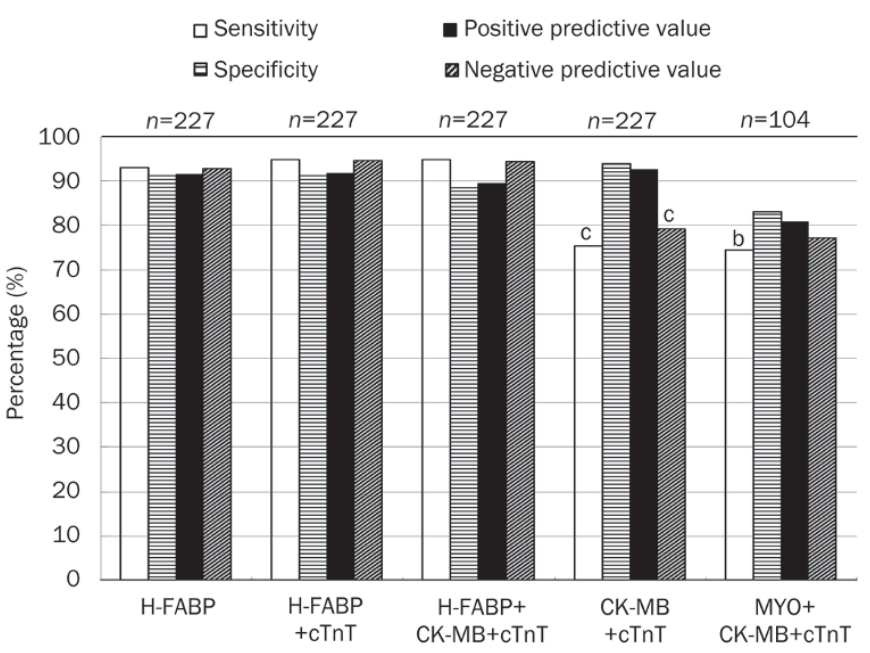

Figure 3. Sensitivity, specificity, positive and negative predictive values of $\mathrm{H}-\mathrm{FABP}$ and different combinations of the biomarkers. Compared with $\mathrm{H}-\mathrm{FABP}+\mathrm{CTnT},{ }^{\mathrm{b}} \mathrm{P}<0.05,{ }^{\mathrm{c}} \mathrm{P}<0.01$ (result from subgroup analysis).

than that of initial CK-MB and cTnT within 3-6 h of symptom onset, which were more significantly higher when patients presented within $3 \mathrm{~h}$ of the chest pain. Conversely, neither of them reached significant difference when patients presented 6-12 $\mathrm{h}$ of the symptom onset. H-FABP+cTnT exhibited the same superiorities over initial $\mathrm{cTnT}$ and $\mathrm{CK}-\mathrm{MB}+\mathrm{cTnT}$ within $3 \mathrm{~h}$ or $3-6 \mathrm{~h}$ of the symptom onset. The sensitivities and negative predictive values of all the single and combined biomarkers increased by time and reached $100 \%$ within $6-12 \mathrm{~h}$ of symptom onset. No differences of the specificities or positive predictive values among single biomarkers or the combinations were found within the same subgroup (Figure 4).

Performances of H-FABP, MYO and the associated combinations Additional detection of MYO were performed in one center, where 51 AMI patients and 53 non-AMI patients were included. The sensitivity of H-FABP was significantly higher than that of MYO [86.3\% (95\% CI: $73.7 \%-94.3 \%)$ vs $68.6 \%(95 \%$ CI: $54.1 \%-80.9 \%) ; P=0.0330]$. The sensitivity of H-FABP+cTnT was significantly higher than that of MYO+CK-MB+cTnT [90.2\% (95\% CI: 78.6\%-96.7\%) vs 74.5\% (95\% CI: $60.4 \%-85.7 \%)$; $P=0.0377$ ] (Figure 2, 3). On the other hand, the negative 

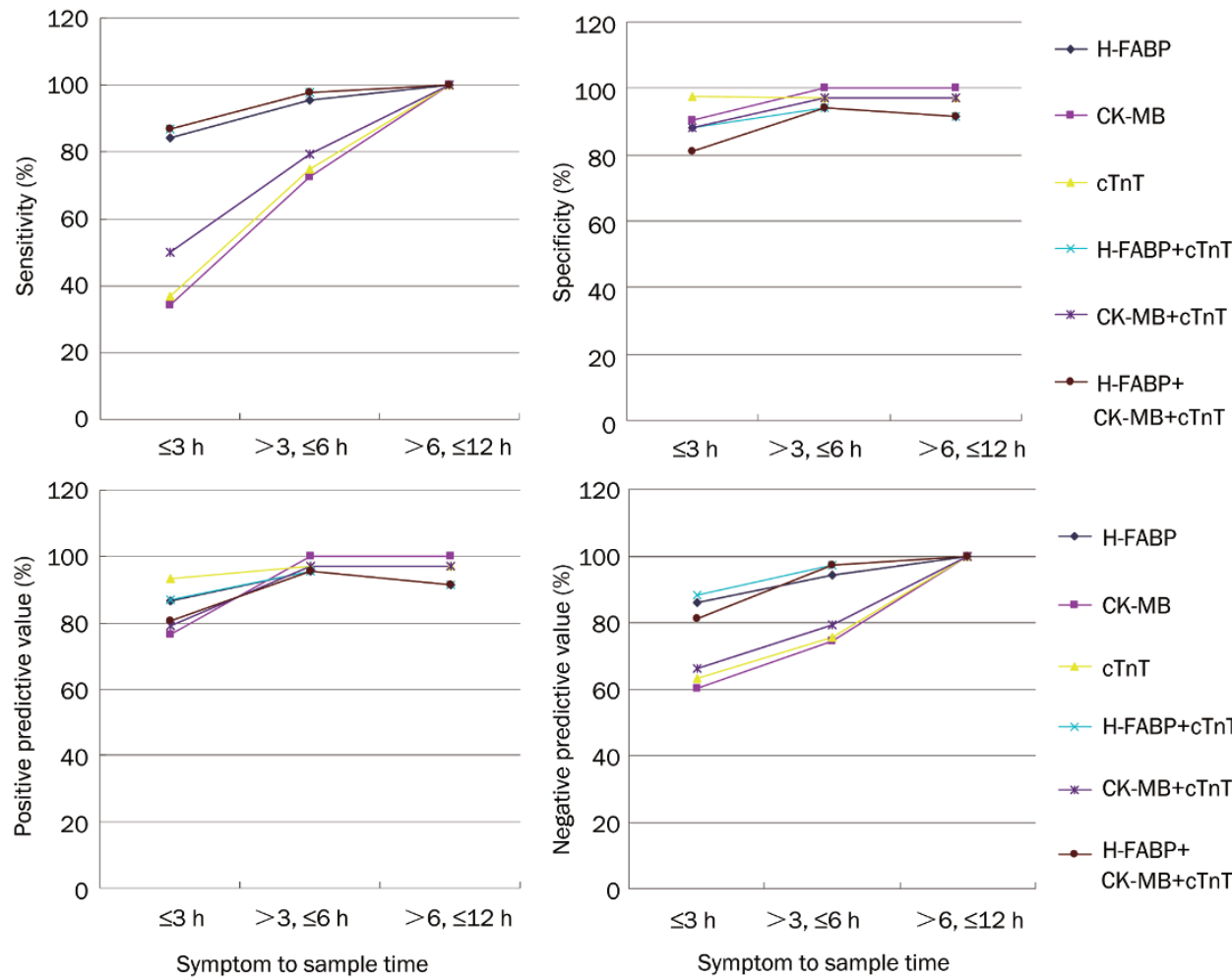

$\bullet$ H-FABP

- CK-MB

- $\mathrm{TnT}$

* H-FABP+cTnT

* CK-MB+cTnT

$\mathrm{H}-\mathrm{FABP}+$ CK-MB+cTnT

Figure 4. Sensitivity, specificity, positive and negative predictive values of the biomarkers in different symptom to sample time-frames.
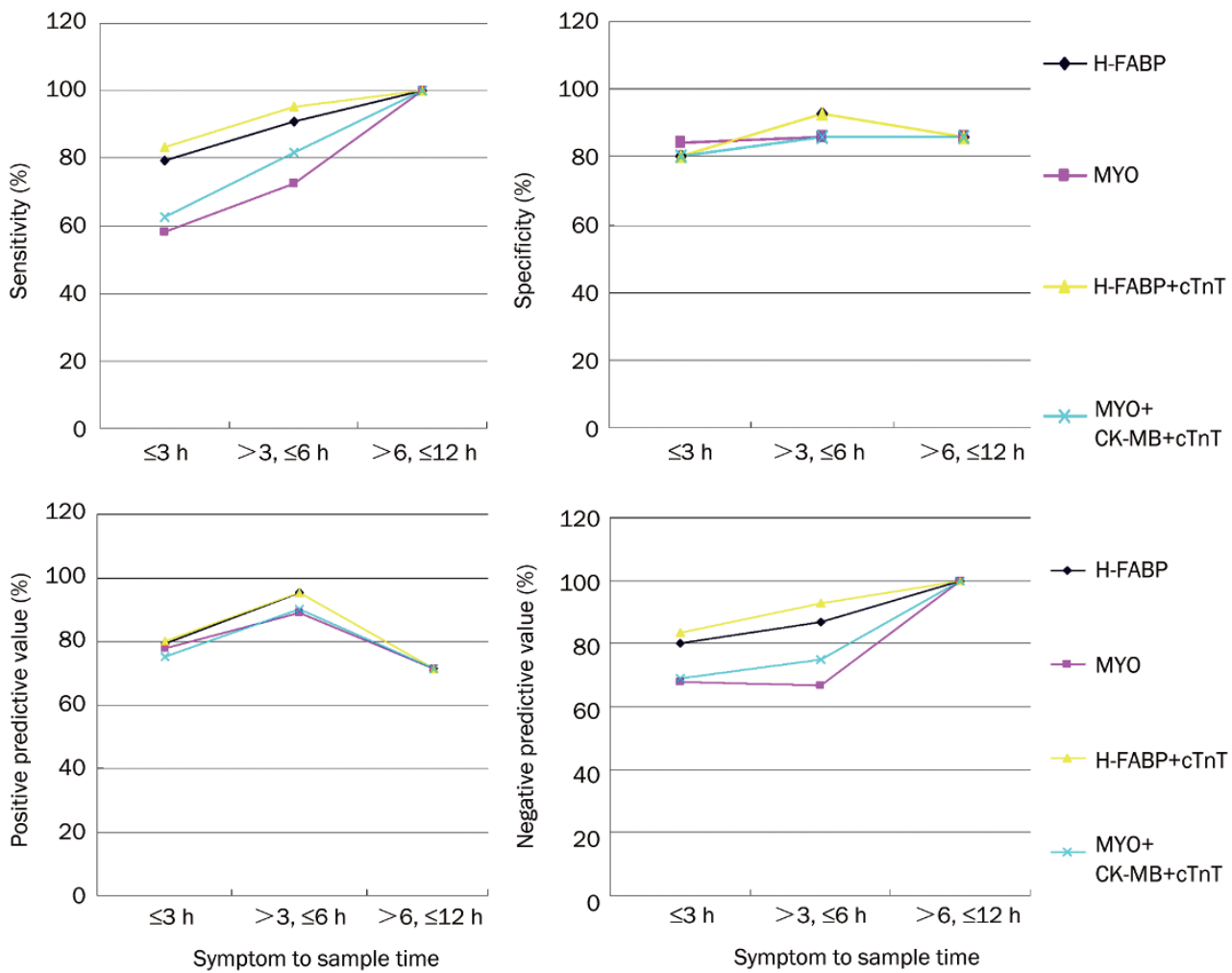

Figure 5. Sensitivity, specificity, positive and negative predictive values of the biomarkers including myoglobin in different symptom to sample timeframes.

predictive value of H-FABP was better than MYO [86.5\% (95\% CI: $74.2 \%-94.4 \%$ ) vs $73.8 \%$ (95\% CI: $60.9 \%-84.2 \%$ ); $P=0.093$ ]. The negative predictive value of $\mathrm{H}-\mathrm{FABP}+\mathrm{cTnT}$ was better than MYO+CK-MB+cTnT [90.0\% (95\% CI: 78.2\%-96.7\%) vs
77.2\% (95\% CI: 64.2\%-87.3\%); P=0.077] (Figure 2, 3).

In the subgroups separated by different symptom to sample time, H-FABP presented better sensitivity and negative predictive value than MYO in patients admitted within $3 \mathrm{~h}$ or 3-6 h. 
$\mathrm{H}-\mathrm{FABP}+\mathrm{CTnT}$ showed the same superiority over MYO+CK$\mathrm{MB}+\mathrm{cTnT}$ within $3 \mathrm{~h}$ or 3-6 h of the symptom onset, although the differences were not statistically significant. The sensitivities and the negative predictive values of H-FABP, MYO and the two combinations all reached $100 \%$ at $6-12 \mathrm{~h}$ of the incidence (Figure 5).

The specificities and the positive predictive values among $\mathrm{H}-\mathrm{FABP}, \mathrm{MYO}, \mathrm{H}-\mathrm{FABP}+\mathrm{cTnT}$ and $\mathrm{MYO}+\mathrm{CK}-\mathrm{MB}+\mathrm{cTnT}$ did not show significant difference in the total subjects or within each subgroup.

\section{Discussion}

This study was conducted in two cardiac centers simultaneously, which disclosed that the performance of point-of-care test of H-FABP was superior to that of CK-MB, CTnT and MYO by providing higher sensitivity and negative predictive values specifically in early stage of AMI ( $\leq 6 \mathrm{~h}$ of the symptom onset). In the mean time, H-FABP+cTnT combination showed significantly higher sensitivity and negative predictive values than that of single cTnT and the regular combinations including CK-MB+cTnT and MYO+CK-MB+cTnT.

Currently used biomarkers such as CK-MB and cTnT are both myocardial construction proteins and have higher cardiac specificity, which have being referred as key cardiac biomarkers for AMI diagnosis ${ }^{[1]}$. However, neither of them can identify AMI until more than $4 \mathrm{~h}$ after onset of the chest pain in most cases ${ }^{[9,10]}$. MYO is more sensitive in the early phase of AMI, but its specificity is not satisfying ${ }^{[9]}$. Thus H-FABP would act as a fewer available cardiac biomarker with superior performance in the diagnosis of early-stage AMI.

The superior performance of H-FABP may be attributed to the following two factors: i) smaller molecular weight: H-FABP is a small cytoplasmic protein, which has a very low molecular weight of $15 \mathrm{kDa}$, while the molecular weight of MYO, CK-MB and $\mathrm{cTnT}$ are 18, 80 and $37 \mathrm{kDa}$ respectively ${ }^{[11-13]}$. ii) steeper tissue-to-plasma gradient: The myocardial content of H-FABP $(0.52 \mathrm{mg} / \mathrm{g}$ wet $\mathrm{wt})$ is 4.5 fold lower than that of myoglobin $(2.35 \mathrm{mg} / \mathrm{g}$ wet $\mathrm{wt})$, yet the basic plasma level of H-FABP $(2.8 \mu \mathrm{g} / \mathrm{L})$ is 10 -fold lower than the later $(30 \mu \mathrm{g} / \mathrm{L})^{[14,15]}$. So H-FABP tissue-to-plasma gradient is at least two-fold steeper than that of myoglobin. This characteristic, along with the higher permeability of the endothelial barrier for small proteins, enable H-FABP to exhibit an early and significant release after myocardial necrosis and make it more easily being detected, thus endue H-FABP with a superior capability for early AMI diagnosis.

However, it has been noted that H-FABP isoform is produced not only in cardiomyocytes but also, to a lesser extent, in skeletal muscle, distal tubular cells of the kidney, specific parts of the brain, lactating mammary glands and the placenta $^{[16]}$. In the clinical studies, serum H-FABP level is also elevated under heart failure, hypertension, aortic valve regurgitation, renal dysfunction and muscular exercise ${ }^{[17-20]}$. Our study demonstrated that H-FABP had a specificity that was slightly lower than CK-MB and CTnT, and was not superior to MYO in any time period within $12 \mathrm{~h}$ after onset of the symptoms. Besides, the positive predictive value of $\mathrm{H}-\mathrm{FABP}$ did not show superiority to MYO, CK-MB or cTnT. Therefore, multiple physiological and pathological factors should be considered while the point-of-care test of H-FABP is applied in AMI diagnosis.

The multi-marker concept was put forward recently in diagnosing AMI, predicting disease risk and evaluating patient outcomes ${ }^{[21,22]}$. Mion et al used an automated protein biochip microarray system, which allowed a simultaneous determination of six biomarkers, and found that H-FABP+CTnI combination presented the highest sensitivity $(83.3 \%)$ and specificity $(92.2 \%)$, and favored it as the most effective "two marker strategy" of the five combinations determined in the study ${ }^{[23]}$. We investigated the performances of different combinations including H-FABP+cTnT , CK-MB+cTnT, MYO+CK-MB+cTnT and $\mathrm{H}-\mathrm{FABP}+\mathrm{CK}-\mathrm{MB}+\mathrm{CTnT}$ in this study. As a result, the $\mathrm{H}-\mathrm{FABP}+\mathrm{CTnT}$ significantly improved the sensitivity and negative predictive value of single $\mathrm{CTnT}$, and exhibited the highest sensitivity and negative predictive value as compared with $\mathrm{CK}-\mathrm{MB}+\mathrm{cTnT}$ and $\mathrm{MYO}+\mathrm{CK}-\mathrm{MB}+\mathrm{cTnT}$ in early phase of AMI $(\leq 6 \mathrm{~h})$. Tri-marker test of H-FABP+CK-MB+cTnT did not improve the sensitivity and negative predictive value of H-FABP+cTnT. Although the specificity and the positive predictive value of $\mathrm{H}-\mathrm{FABP}+\mathrm{cTnT}$ were not superior to that of other combinations, it was not inferior to that of any single cardiac marker or combination. These findings suggested that $\mathrm{H}-\mathrm{FABP}+\mathrm{cTnT}$ was currently the most effective combination for the diagnosis of early AMI.

One limitation of this study was that we only assessed the performance of H-FABP from single measurement on the participants, sequential measurements were not performed, so the performances of H-FABP in different time windows were evaluated from different subjects, while not a dynamic investigation of the same population.

In conclusion, our study demonstrated that the point-of-care test of H-FABP was a more sensitive test for the AMI diagnosis compared with conventional cardiac markers, which can be used as a valuable biomarker to exclude an early-stage AMI (within $6 \mathrm{~h}$ after onset of the symptoms). Combining H-FABP and $\mathrm{CTnT}$ provides the best performance for early AMI diagnosis.

\section{Acknowledgments}

We thank the staff of the coronary heart disease ward of the First Affiliated Hospital of Nanjing Medical University, and those of the Affiliated Hospital of Guiyang Medical College for helping us to collect the blood samples and the related data. We also thank the laboratory personnel for the assistance of analyzing the serum levels of MYO, CK-MB and cTnT.

\section{Author contribution}

Chun-jian LI, Zhi-jian YANG, ,Ke-jiang CAO, Jun HUANG designed research; Chun-jian LI, Jie-qi LI, Xiao-fang LIANG, Xiao-xiang LI, Jian-guo CUI performed research; Chun-jian LI, Qing GUO analyzed data; Chun-jian LI wrote the paper. 


\section{References}

1 Thygesen K, Alpert JS, White HD; Joint ESC/ACCF/AHA/WHF Task Force for the Redefinition of Myocardial Infarction. Universal definition of myocardial infarction. J Am Coll Cardiol 2007; 50: 2173-95.

2 Anderson JL, Adams CD, Antman EM, Bridges CR, Califf RM, Casey DE Jr, et al. ACC/AHA 2007 guidelines for the management of patients with unstable angina/non ST-elevation myocardial infarction: a report of the American College of Cardiology/American Heart Association Task Force on Practice Guidelines (Writing Committee to Revise the 2002 Guidelines for the Management of Patients With Unstable Angina/Non ST-Elevation Myocardial Infarction): developed in collaboration with the American College of Emergency Physicians, the Society for Cardiovascular Angiography and Interventions, and the Society of Thoracic Surgeons: endorsed by the American Association of Cardiovascular and Pulmonary Rehabilitation and the Society for Academic Emergency Medicine. Circulation 2007; 116: e148-304.

3 Boden WE, Eagle K, Granger CB. Reperfusion strategies in acute STsegment elevation myocardial infarction: a comprehensive review of contemporary management options. J Am Coll Cardiol 2007; 50: 917-29.

4 Yang EH, Brilakis ES, Reeder GS, Gersh BJ. Modern management of acute myocardial infarction. Curr Probl Cardiol 2006; 31: 769-817.

5 Glatz JF, van der Vusse GJ. Cellular fatty acid-binding proteins: their function and physiological significance. Prog Lipid Res 1996; 35 : 243-82.

6 Pelsers MM, Hermens WT, Glatz JF. Fatty acid-binding proteins as plasma markers of tissue injury. Clin Chim Acta 2005; 352: 15-35.

7 Seino Y, Tomita Y, Takano T, Ohbayashi K. Tokyo Rapid-Test Office Cardiologists (Tokyo-ROC) Study. Office cardiologists cooperative study on whole blood rapid panel tests in patients with suspicious acute myocardial infarction: comparison between heart-type fatty acid-binding protein and troponin T tests. Circ J 2004; 68: 144-8.

8 Fraker TD Jr, Finn SD; 2002 Chronic Stable Angina Writing Committee; American College of Cardiology; American Heart Association, Gibbons RJ, et al. 2007 chronic angina focused update of the ACC/AHA 2002 guidelines for the management of patients with chronic stable angina: a report of the American College of Cardiology/American Heart Association Task Force on Practice Guidelines Writing Group to develop the focused update of the 2002 guidelines for the management of patients with chronic stable angina. J Am Coll Cardiol 2007; 50: 2264-74.

9 Panteghini M. Role and importance of biochemical markers in clinical cardiology. Eur Heart J 2004; 25: 1187-96.

10 Plebani M. Biochemical markers of cardiac damage: from efficiency to effectiveness. Clin Chim Acta 2001; 311: 3-7.

11 Wodzig KW, Kragten JA, Hermens WT, Glatz JF, van Dieijen-Visser MP.
Estimation of myocardial infarct size from plasma myoglobin or fatty acid-binding protein. Influence of renal function. Eur J Clin Chem Clin Biochem 1997; 35: 191-8.

12 Glatz JF, Kleine AH, van Nieuwenhoven FA, Hermens WT, van DieijenVisser MP, van der Vusse GJ. Fatty-acid-binding protein as a plasma marker for the estimation of myocardial infarct size in humans. $\mathrm{Br}$ Heart J 1994; 71: 135-40.

13 Michielsen EC, Diris JH, Kleijnen VW, Wodzig WK, Van Dieijen-Visser MP. Interpretation of cardiac troponin T behaviour in size-exclusion chromatography. Clin Chem Lab Med 2006; 44: 1422-7.

14 Okamoto F, Sohmiya K, Ohkaru Y, Kawamura K, Asayama K, Kimura H, et al. Human heart-type cytoplasmic fatty acid-binding protein (H-FABP) for the diagnosis of acute myocardial infarction. Clinical evaluation of $\mathrm{H}-\mathrm{FABP}$ in comparison with myoglobin and creatine kinase isoenzyme MB. Clin Chem Lab Med 2000; 38: 231-8.

15 Van Nieuwenhoven FA, Kleine AH, Wodzig WH, Hermens WT, Kragten HA, Maessen JG, et al. Discrimination between myocardial and skeletal muscle injury by assessment of the plasma ratio of myoglobin over fatty acid-binding protein. Circulation 1995; 92: 2848-54.

16 Azzazy HM, Pelsers MM, Christenson RH. Unbound free fatty acids and heart-type fatty acid-binding protein: diagnostic assays and clinical applications. Clin Chem 2006; 52: 19-29.

17 Arimoto T, Takeishi Y, Shiga R, Fukui A, Tachibana H, Nozaki N, et al. Prognostic value of elevated circulating heart-type fatty acid binding protein in patients with congestive heart failure. J Card Fail 2005; 11 : 56-60.

18 lida M, Yamazaki M, Honjo H, Kodama I, Kamiya K. Predictive value of heart-type fatty acid-binding protein for left ventricular remodelling and clinical outcome of hypertensive patients with mild-to-moderate aortic valve diseases. J Hum Hypertens 2007; 21: 551-7.

19 Niizeki T, Takeishi Y, Takabatake N, Shibata Y, Konta T, Kato T, et al. Circulating levels of heart-type fatty acid-binding protein in a general Japanese population: effects of age, gender, and physiologic characteristics. Circ J 2007; 71: 1452-7.

20 Delacour H, Nervale A, Servonnet A, Pagliano B, Dehan C, Gardet V. Variations of plasma concentrations of h-FABP during a muscular exercise. Ann Biol Clin (Paris) 2007; 65: 27-32.

21 Mion MM, Novello E, Altinier S, Rocco S, Zaninotto M, Plebani M. Analytical and clinical performance of a fully automated cardiac multimarkers strategy based on protein biochip microarray technology. Clin Biochem 2007; 40: 1245-51.

22 Vittorini S, Clerico A. Cardiovascular biomarkers: increasing impact of laboratory medicine in cardiology practice. Clin Chem Lab Med 2008; 46: 748-63.

23 Vasan RS. Biomarkers of cardiovascular disease: molecular basis and practical considerations. Circulation 2006; 113: 2335-62. 